Supplemental Information

\title{
Aerosol Charge Fractions Downstream of Six Bipolar Chargers: Effects of Ion Source, Source Activity, and Flowrate
}

Jingkun Jiang ${ }^{1,2 *}$, Chungman $\mathrm{Kim}^{2}$, Xiaoliang Wang ${ }^{3,4}$, Mark R. Stolzenburg ${ }^{2}$, Stanley L. Kaufman ${ }^{4}$, Chaolong $\mathrm{Qi}^{2}$, Gilmore J. Sem ${ }^{4}$, Hiromu Sakurai ${ }^{5}$, Naoya Hama ${ }^{6}$, and Peter H. McMurry ${ }^{2}$

${ }^{1}$ State Key Joint Laboratory of Environment Simulation and Pollution Control, School of Environment, Tsinghua University, Beijing, China;

${ }^{2}$ Department of Mechanical Engineering, University of Minnesota, Minneapolis, MN, U.S.A.;

${ }^{3}$ Desert Research Institute, Reno, NV, U.S.A.;

${ }^{4}$ TSI Inc., Shoreview, MN, U.S.A.;

${ }^{5}$ National Institute of Advanced Industrial Science and Technology, Tsukuba, Japan;

${ }^{6}$ Tokyo Dylec Corp., Tokyo, Japan

*To whom correspondence should be addressed:

Email: jiangjk@tsinghua.edu.cn

Tel: $+86-10-62781512$ 
Table S1 Summary of the radioactive sources investigated

\begin{tabular}{c|ccc}
\hline $\begin{array}{c}\text { Neutralizers } \\
\text { (initial activity) }\end{array}$ & $\begin{array}{c}\text { Age } \\
\text { (Month) }\end{array}$ & $\begin{array}{c}\text { Number of } \\
\text { half lives }\end{array}$ & $\begin{array}{c}\text { Nominal } \\
\text { Activity }(\mathrm{MBq})\end{array}$ \\
\hline & 4 & 0.867 & 10.142 \\
& 10 & 2.168 & 4.117 \\
${ }^{210} \mathrm{Po}$ & 16 & 3.469 & 1.671 \\
& 28 & 6.070 & 0.275 \\
$(18.5 \mathrm{MBq} / 0.5 \mathrm{mCi})$ & 52 & 8.455 & 0.0527 \\
& 64 & 11.273 & 0.0075 \\
& 77 & 16.693 & 0.0012 \\
& 91 & 19.728 & $2.1 \times 10^{-5}$ \\
\hline${ }^{85} \mathrm{Kr} 3077 \mathrm{~A}$ & 4 & 0.031 & 362.11 \\
$(370 \mathrm{MBq} / 10 \mathrm{mCi})$ & 25 & 0.194 & 323.37 \\
\hline${ }^{85} \mathrm{Kr} 3077$ & 29.5 & 0.229 & 315.62 \\
\hline$(74 \mathrm{MBq} / 2 \mathrm{mCi})$ & 5.5 & 0.043 & 71.839 \\
${ }^{85} \mathrm{Kr} 3012 \mathrm{~A}$ & 127 & 0.987 & 37.328 \\
\hline$(370 \mathrm{MBq} / 10 \mathrm{mCi})$ & 6 & 0.047 & 358.23 \\
\hline${ }^{85} \mathrm{Kr} 3012$ & 6.5 & 0.051 & 71.453 \\
$(74 \mathrm{MBq} / 2 \mathrm{mCi})$ & 53.5 & 0.416 & 55.467 \\
\hline${ }^{241} \mathrm{Am}$ & 4 & 0.0008 & 2.997 \\
$(3 \mathrm{MBq} / 0.08 \mathrm{mCi})$ & & & \\
\hline
\end{tabular}

Note:

1.) $\mathrm{Bq}$ is the $\mathrm{SI}$ unit of radioactivity. One $\mathrm{Bq}$ is defined as one transformation (or decay or disintegration) per second. Curie (Ci) is another unit of radioactivity. $1 \mathrm{Ci}=3.7 \times 10^{10} \mathrm{~Bq}$.

2.) The half lives of ${ }^{210} \mathrm{Po},{ }^{85} \mathrm{Kr}$, and ${ }^{241} \mathrm{Am}$ are 4.6 months, 128.6 months, and 432.2 years, respectively.

3.) ${ }^{210} \mathrm{Po}$ and ${ }^{241} \mathrm{Am}$ emit monoenergetic alpha particles with energy around 5 $\mathrm{MeV} .{ }^{85} \mathrm{Kr}$ emits beta particles with continuous energy distribution up to 0.69 $\mathrm{MeV}$. The photon energy of soft X-ray is $\sim 9.5 \mathrm{keV}$. 

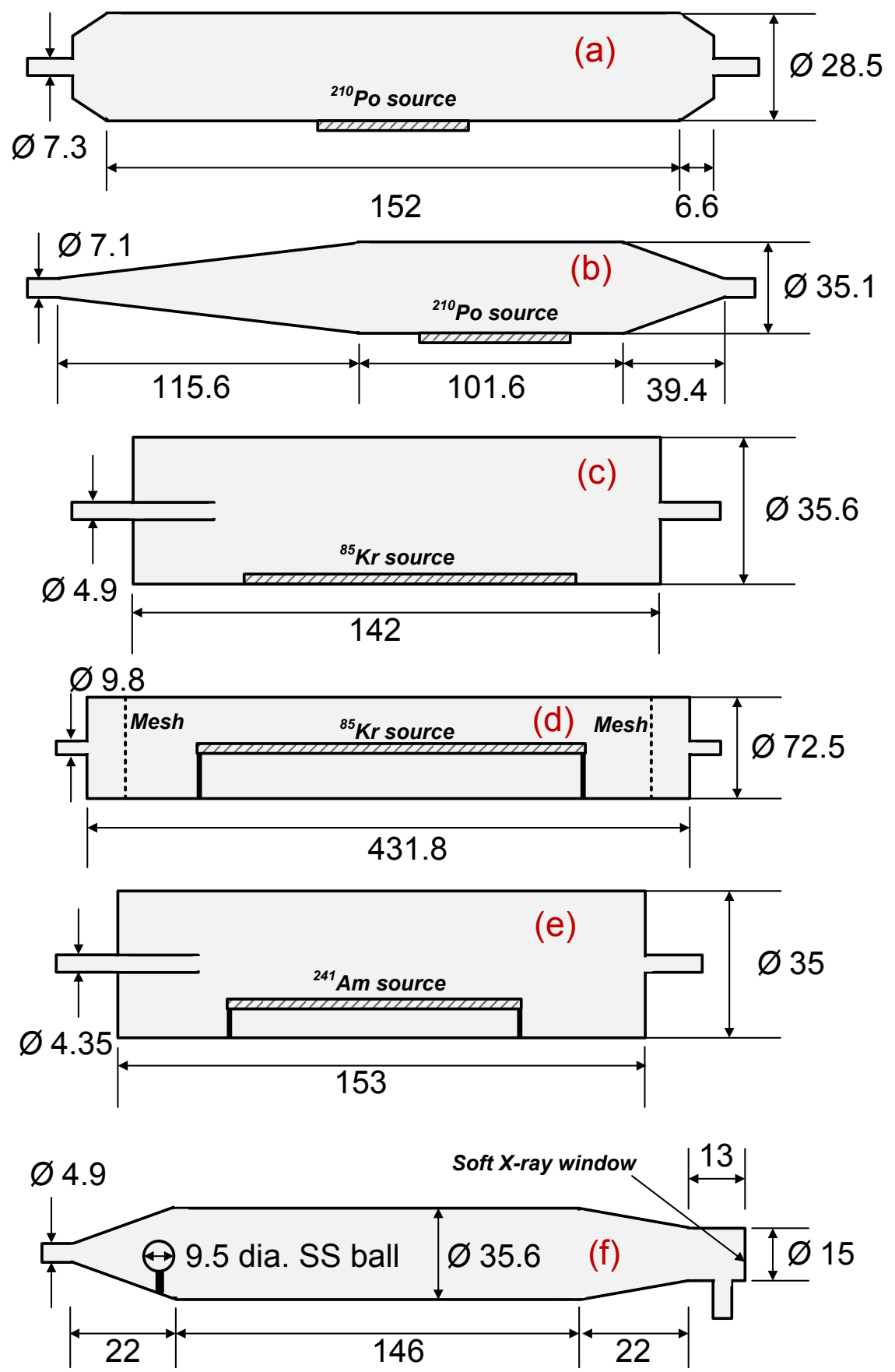

Figure S1 Inside dimensions of the test neutralizer housings (flow from left to right): (a) ${ }^{210}$ Po housing of Particle Technology Laboratory (PTL); (b) ${ }^{210}$ Po housing of Aerosol Dynamics (ADI); (c) ${ }^{85} \mathrm{Kr}$ housing of TSI 3077/3077A; (d) ${ }^{85} \mathrm{Kr}$ housing of TSI 3012/3012A; (e) ${ }^{241}$ Am housing of Tokyo Dylec Corporation; (f) soft X-ray housing of TSI 3087. For PTL and ADI neutralizers, radioactive sources are placed in cavities of housing walls. The drawings are NOT proportional to their dimensions. Unit: $\mathrm{mm}$. 

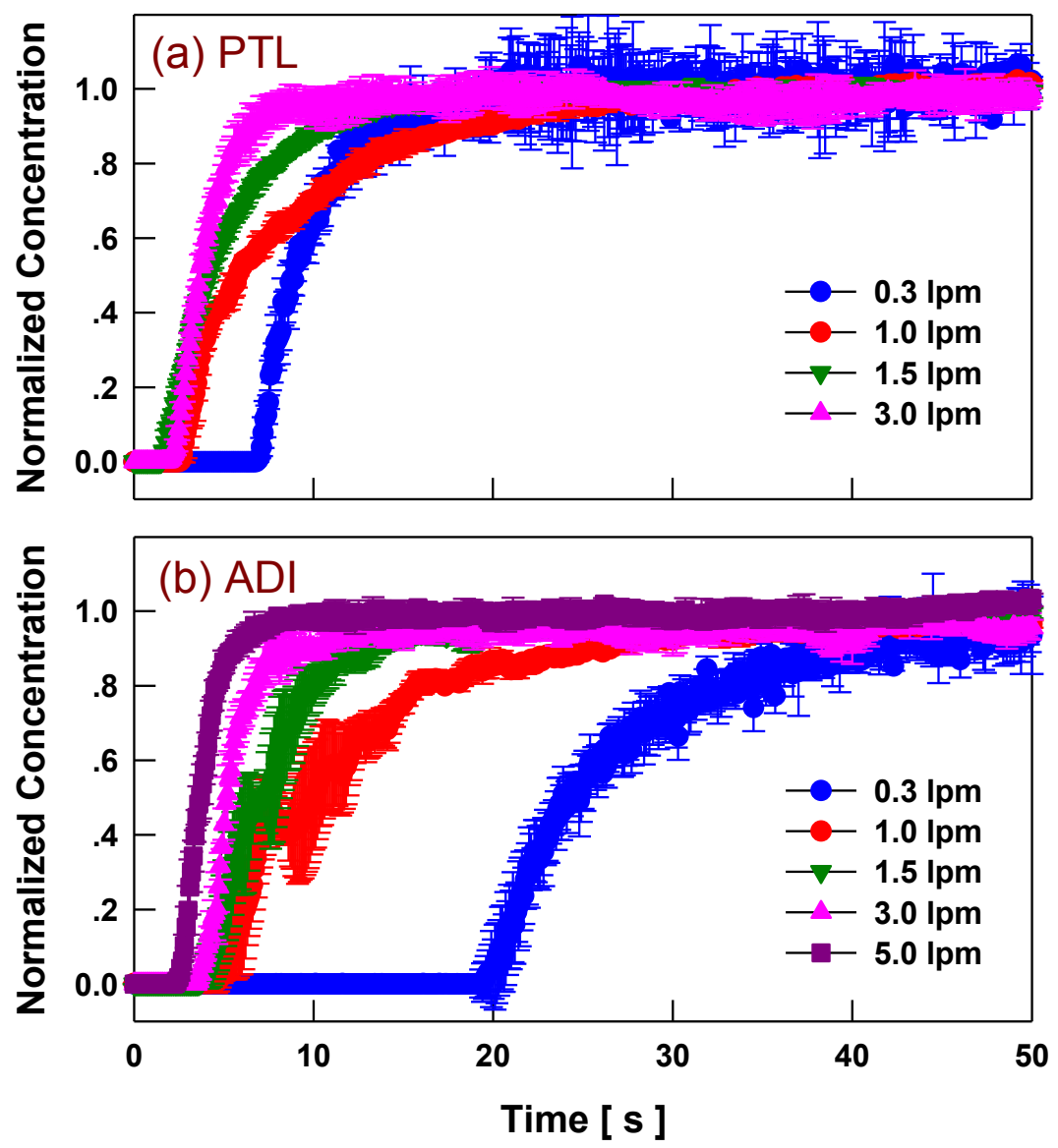

Figure S2 Particle concentrations downstream of the PTL (a) and ADI (b) neutralizers corresponding to step increase in upstream particle concentrations. Sodium chloride particles were generated by atomization, and classified by a DMA to select $50 \mathrm{~nm}$ particles. The DMA voltage was turned on and off every five minutes to generate step changes in particle concentrations at the inlet of the neutralizers. Particle concentrations at the outlet of the neutralizers were measured by a CPC. The concentrations were normalized by the average concentration for the last $100 \mathrm{~s}$ at the step plateau. The error bar represents the standard deviation of 3-4 replicates for a given flowrate. The ADI outlet concentration shows significant variations in concentrations for flowrates of 1 and $1.5 \mathrm{lpm}$, indicating flow instabilities inside the neutralizer. 

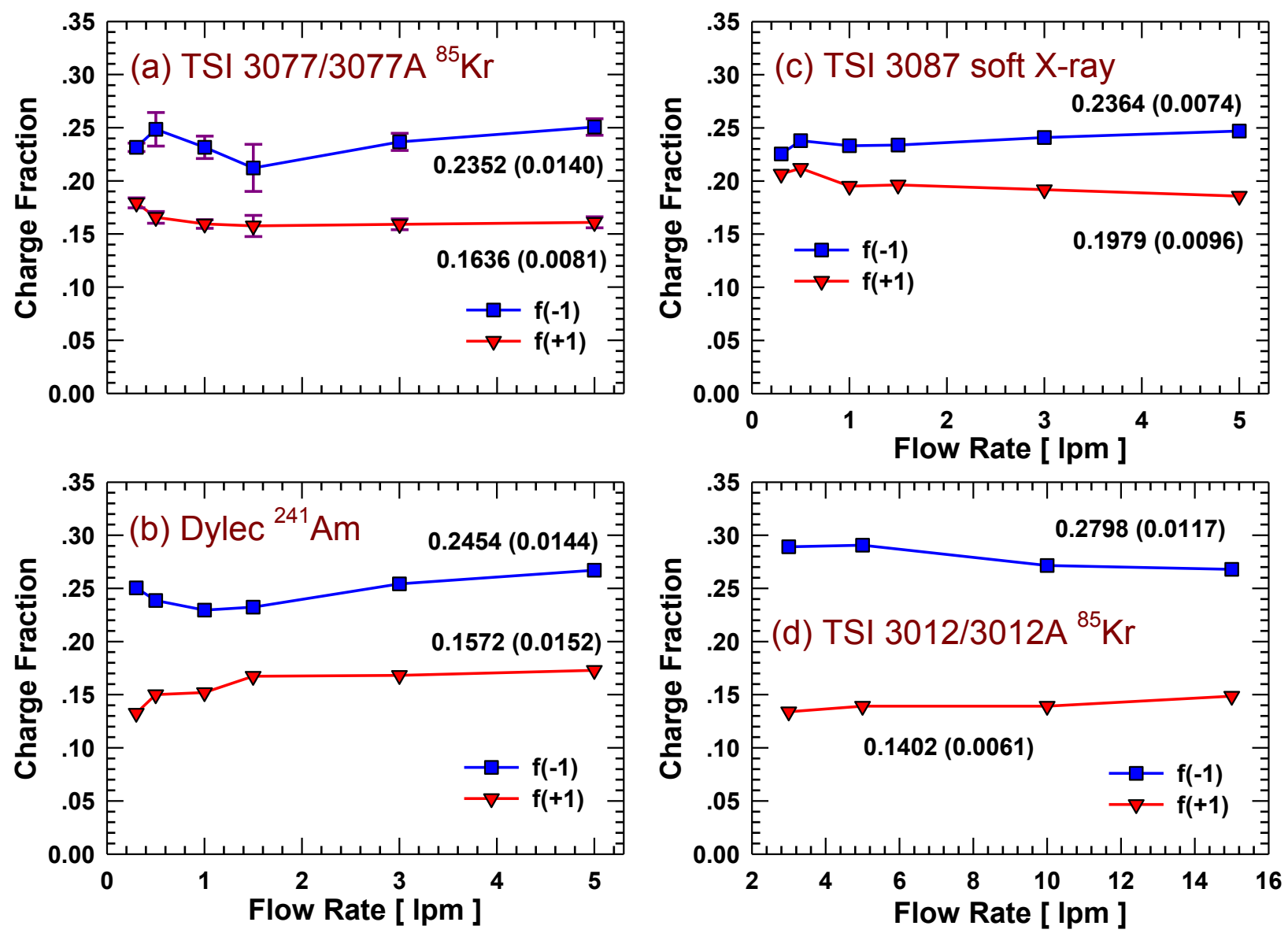

Figure S3 Singly charged fractions of $70 \mathrm{~nm}$ particles with different neutralizers as a function of the aerosol flowrate: (a) TSI 3077/3077A ${ }^{85} \mathrm{Kr}$ neutralizer; (b) Dylec ${ }^{241}$ Am neutralizer; (c) TSI 3087 soft X-ray neutralizer; (d) TSI 3012/3012A ${ }^{85} \mathrm{Kr}$ neutralizer. For ${ }^{85} \mathrm{Kr}$ neutralizers, charge fractions are averaged for all tested ${ }^{85} \mathrm{Kr}$ sources with activity greater than $70 \mathrm{MBq}$. The error bars in (a) are the standard deviations. Numbers given on the plots are the mean charge fraction for all flowrates and the standard deviation (in parenthesis), respectively. 

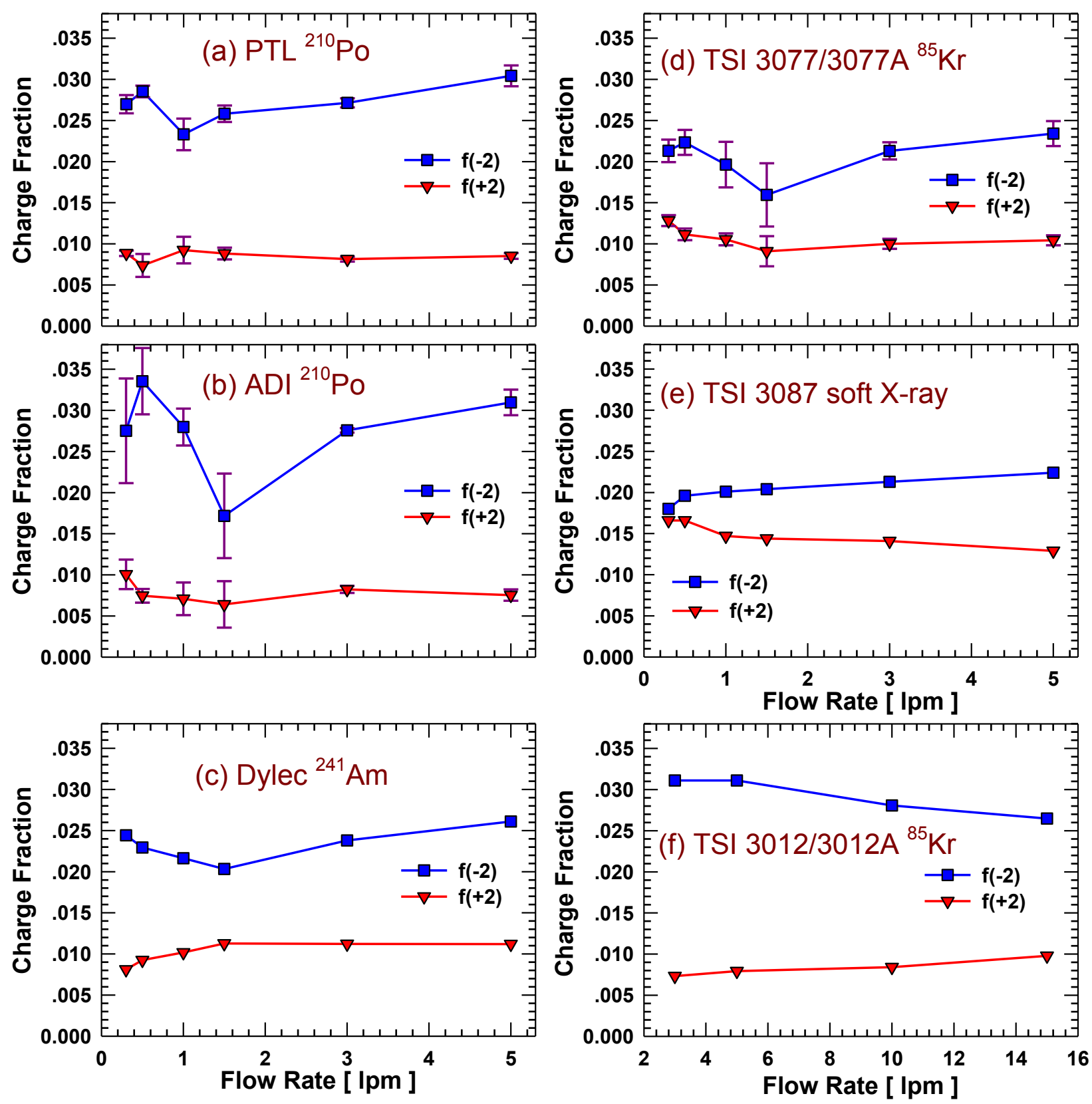

Figure S4 Doubly charged fractions of $70 \mathrm{~nm}$ particles with different neutralizers as a function of the aerosol flowrate: (a) PTL ${ }^{210}$ Po neutralizer; (b) ADI ${ }^{210}$ Po neutralizer; (c) Dylec ${ }^{241} \mathrm{Am}$ neutralizer; (d) TSI 3077/3077A ${ }^{85} \mathrm{Kr}$ neutralizer; (e) TSI 3087 soft X-ray neutralizer; (f) TSI 3012/3012A ${ }^{85} \mathrm{Kr}$ neutralizer. For the ${ }^{210}$ Po neutralizer, charge fractions are averaged for all test ${ }^{210} \mathrm{Po}$ sources with the activity of $0.0527 \mathrm{MBq}$ or greater. For ${ }^{85} \mathrm{Kr}$ neutralizers, charge fractions are averaged for all tested ${ }^{85} \mathrm{Kr}$ sources with the activity greater than $70 \mathrm{MBq}$. The error bars in (a), (b), and (d) are the standard deviations. 